\title{
Contrast Media Extravasation in CT and MRI - A Literature \\ Review and Strategies for Therapy
}

\section{Kontrastmittel Paravasat bei CT und MRT - Aktuelle Literaturübersicht und Behandlungsstrategien}

Authors

Veronika Mandlik ${ }^{1}$, Lukas Prantl ${ }^{1}$, Andreas G. Schreyer ${ }^{2}$

Affiliations

1 Center of Plastic-, Hand- and Reconstructive Surgery, University Hospital Regensburg, Germany

2 Department of Radiology, University Hospital Regensburg, Germany

Key words

$\mathrm{CT}$, contrast agents, extravasation

received 01.08.2017

accepted 13.04.2018

Bibliography

DOI https://doi.org/10.1055/a-0628-7095

Published online: 18.6.2018

Fortschr Röntgenstr 2019; 191: 25-32

(c) Georg Thieme Verlag KG, Stuttgart · New York

ISSN 1438-9029

Correspondence

Prof. Andreas G. Schreyer

Department of Radiology, University Medical Center

Regensburg, Franz-Josef-Strauss-Allee 11,

93053 Regensburg, Germany

Tel.: ++49/941/9447442

andreas.schreyer@klinik.uni-regensburg.de

\section{ABSTRACT}

Background Contrast extravasation events in daily radiological routine may lead to serious complications, especially during $\mathrm{CT}$ examinations. The resulting symptoms may vary from local pain up to skin ulcers, necrosis or even acute compartment syndrome.

There are no uniformly accepted radiological guidelines or recommendations regarding detection and treatment of extravasation events and immanent complications in a timely manner.

Method Systematic literature research considering the last 35 years via PubMed using search terms "contrast medium extravasation/paravasation".

Results In the literature, there are conservative management approaches of contrast media extravasation without major evidence base, such as unguent dressings, cooling or splint- ing. This therapy is mostly symptomatic. Additionally, various invasive techniques are described. We discuss these techniques in the context of contemporary literature, such as the hyaluronidase Injection into the site of extravasation, suction/ aspiration technique including flushing of the affected tissue areas and the squeezing technique. However, most citations lack scientific evidence: many articles include anecdotal enumerations, case studies or cite publications from the era, when ionic high osmolar contrast media was state-of-the-art. Besides, many authors derive their extravasation management from studies, where agents other than contrast media were investigated.

Conclusion After detailed literature review, we suggest early (plastic) surgical consultation when non-ionic, low-osmolar contrast medium extravasation is about $150 \mathrm{cc}$ or more. In case of extravasation less than $150 \mathrm{cc}$ but in presence of additional symptoms such as impaired perfusion or altered sensibility, the (plastic) surgeon should also be consulted instantly. We do not recommend any invasive first line therapy when contrast media extravasation is less than $150 \mathrm{cc}$ and the patient presents no additional symptoms, besides swelling and local pain. Nevertheless continuous monitoring and accurate conservative management such as active cooling and elevation, splinting of the affected extremity are mandatory as early detection of critical symptoms helps to initiate prompt surgical intervention and avoid sequelae.

\section{Key Points}

- Morbidity after contrast media extravasation is extremely rare.

- Predicting sequelae after contrast extravasation is difficult at first sight.

- Treatments such as hyaluronidase injection, suction/aspiration, squeeze technique have been described.

- Surgical consultation is recommended for extravasation $>150$ cc or when additional symptoms occur.

\section{Citation Format}

- Mandlik V, Prantl L, Schreyer AG. Contrast Media Extravasation in CT and MRI - A Literature Review and Strategies for Therapy. Fortschr Röntgenstr 2019; 191: 25-32 


\section{ZUSAMMENFASSUNG}

Hintergrund Kontrastmittel-Paravasate stellen in der radiologischen Routine v. a. bei CT-Untersuchungen ein nicht zu unterschätzendes Problem im klinischen Alltag dar. Die daraus resultierenden Komplikationen können von lokalen Schmerzen bis zu extrem seltenen, jedoch schwerwiegenden Komplikationen wie Kompartmentsyndrom, Nekrose oder Ulzeration führen.

Es existieren keine einheitlichen radiologischen Empfehlungen oder Richtlinien, um Paravasat-Ereignisse mit drohenden komplizierten Verläufen frühzeitig zu erkennen bzw. korrekt zu therapieren.

Methode Systematische Literaturrecherche der letzten 35 Jahre via PubMed über die Suchbegriffe „contrast media extravasation/paravasation“.

Ergebnisse In der Literatur finden sich konservative Therapieansätze, wie etwa Salbenverbände, Kühlung oder Schienung, für die meist keine Evidenz vorliegt und die eher als symptomatisch zu betrachten sind. Als invasive Verfahren werden diverse Methoden beschrieben, die wir in der Übersichtsarbeit detailliert im Kontext der aktuellen Literatur erläutern. Hier gehen wir besonders auf die Hyaluronidase-Injektion in das Paravasatgebiet, die Suktion/Aspiration des Paravasats mit anschließender Spülung und die AusmelkTechnik ein. Häufig liegt bei den Literaturangaben nur man- gelnde Evidenz bei der Behandlung von Kontrastmittel-Paravasaten vor. Dabei handelt es sich oft um anekdotische Aufzählungen mehrerer Fälle bzw. Zitate aus Zeiten, in denen noch ionisches hochosmolares Kontrastmittel verwendet wurde. Zusätzlich werden in vielen Publikationen Behauptungen über das gängige Vorgehen bei Paravasaten basierend auf den Daten von anderen Medikamenten und Substraten kritiklos übernommen.

Schlussfolgerung Nach umfassender Literatur-Recherche empfehlen wir die konsiliarische Beurteilung eines Paravasats durch einen (plastischen) Chirurgen ab einem ausgetretenen Volumen von etwa $150 \mathrm{ml}$ nicht ionischen Röntgenkontrastmittels. Zusätzlich sollte frühzeitig ein (falls möglich plastisch-) chirurgisches Konsil bereits bei kleineren Volumina durchgeführt werden, wenn eine simultan auftretende Beeinträchtigung des Gewebes mit Störung der Sensibilität oder Perfusion evident wird. Prinzipiell sind invasive Therapien (Hyaluronidase-Injektion, Absaugungs- oder Ausmelk-Technik) bei Paravasatmengen $<150 \mathrm{ml}$ und fehlenden Perfusionsbzw. Sensibilitätseinschränkungen nicht indiziert. Ein konservatives Management in Form von Hochlagerung der Extremität, aktiver Kühlung, ggf. Schienenruhigstellung und vor allem regelmäßiger Kontrolle sind jedoch wichtig, um im Falle von Befundverschlechterungen rechtzeitig eine chirurgische invasive Therapie einzuleiten und Folgeschäden zu vermeiden.

\section{Introduction}

Intravenous application of extracellular contrast media to perform $\mathrm{CT}$ and MRI examinations currently has significant relevance to many clinical issues [1].

A residual risk of extravasation persists despite preventive measures used in radiological clinical routine, such as the administration of an intravenous test bolus prior to high-pressure injection of contrast medium [2]. Studies by Lewis and Hecker [3] demonstrated two types of extravasation mechanisms. On the one hand, fluid can escape into the surrounding tissue through an extraluminally dislocated or perforated catheter tip; on the other hand, it can leak through the puncture site of an intraluminally correctly placed the catheter.

The proper medical procedure after detection of extravasation is often difficult to assess, since extent and consequences at first sight can be varied and misleading. This uncertainty has led to the publication of various therapy suggestions and action algorithms [4 - 10] which usually identify retrospectively-determined thresholds indicating a particularly high risk of serious damage and legitimizing an invasive procedure. Many of the therapy suggestions in the context of contrast agent extravasation mentioned in the literature have been extrapolated from generalized extravasation therapy, which is based primarily on the procedure for extravasation after the administration of chemotherapeutic agents or electrolyte solutions.

In the review of all procedures and techniques, it is striking that the identified thresholds and recommendations for action have often been adopted regardless of the chemical properties of various contrast agents and in particular, invasive therapy concepts were never compared with conservative procedures in randomized control studies. Furthermore, related therapy recommendations are based partly on publications dating from before 1990 , when automatic pressure injections were not the standard, and non-ionic, low-osmolar contrast media were not routinely employed.

\section{Contrast media extravasation in radiology}

Particularly at risk are patients with an inadequate response to pain. High-risk patients also include persons with atrophic, subcutaneous adipose tissue, limited peripheral vascular status or pathological lymphatic situation, as well as patients after current or ongoing chemotherapy with resulting fragile vascular status and clinically difficult to assess skin color [11]. The incidence of extravasation with the use of iodine-based contrast media varies in the literature, and is higher for mechanical bolus injection when compared to manual administration. Thus the data in the literature ranges from $0.1 \%$ to $0.9 \%$ [12-14]. The changeover to automatic pressure injection, among other things, is mentioned as the reason for a higher incidence. In addition, higher injection rates are cited as a reason, even though there are studies that could not prove a connection between the injection rate and extravasation [15]. Of approximately 350000 contrast medium injections for CT examinations, 451 resulted in extravasation 
[16]. The extravasation rate was $0.13 \%$; among women it was $0.15 \%$, somewhat higher than for men, at $0.11 \%$. Severe complications occurred in only a single case. In general, depending on the location, toxicity of the administered agent, volume, osmolarity and state of charge (ionic versus non-ionic), extravasation can lead to negligible or even serious complications [17]. Clinical symptoms can range from mild erythema to soft tissue necrosis ( $\triangleright$ Fig. 1), compartment syndrome [18] or ischemia of an extremity [19]. There are very few articles in the literature describing extravasation complications during MRI examinations. This may be due to the significantly slower injection rate and reduced volumes with low osmolarity used for MRI [6]. Nevertheless, extravasation of gadopentate dimeglumine (Gd-DTPA) can result in edema, necrosis or hemorrhaging [20]. According to Shaqdan et al. the incidence of extravasation during MRI was $0.06 \%$ (90 cases after 150000 injections). None of the documented events resulted in severe complications [16].

In addition to volume and cytotoxicity, osmolarity is considered an essential component with respect to pathological changes related to extravasation. Contrast media between $290-860$ $\mathrm{mOsm} / \mathrm{kg} \mathrm{H} \mathrm{H}_{2} \mathrm{O}$ are considered low osmolar; media between 1200 to $2400 \mathrm{mOsm} / \mathrm{kg} \mathrm{H} \mathrm{H}_{2} \mathrm{O}$ are high osmolar [21]. There is a known direct relationship between osmolarity and cellular lysis. Due to the somewhat serious side effects of ionic, hyperosmolar contrast media, at present non-ionic, low-osmolar contrast agents are primarily used in routine radiological diagnostics [11, 22].

In the following, conservative therapeutic measures will be presented and discussed in the context of the literature. The most important invasive procedures mentioned in the literature in connection with contrast medium extravasation are described and discussed critically. The aim is to evaluate these methods in terms of their relevance in accordance with currently used contrast media and technical standards.

\section{Conservative therapeutic approaches to treating contrast medium extravasation}

There are few meaningful scientific studies on conservative noninvasive therapeutic procedures to treat contrast medium extravasation. However since all the procedures described below contribute to alleviating pain and possibly preventing possible further deterioration in general in the sense of "good clinical practice", we generally recommend their use in routine treatment of extravasation.

In addition to documentation, the following conservative measures [4] should be employed immediately after extravasation has been determined:

- Aspiration attempt while the catheter is still in place [23] then removal

- Raising of the affected limb (if possible above heart level) to reduce edema by reducing hydrostatic capillary pressure [7]

- Moderate cooling in the region of the extravasation.

The literature discuses both the application of cold as well as heat. Whereas active warming theoretically results in vasodilation and resorption of the leaked medium, and thus to a reduction of asso-

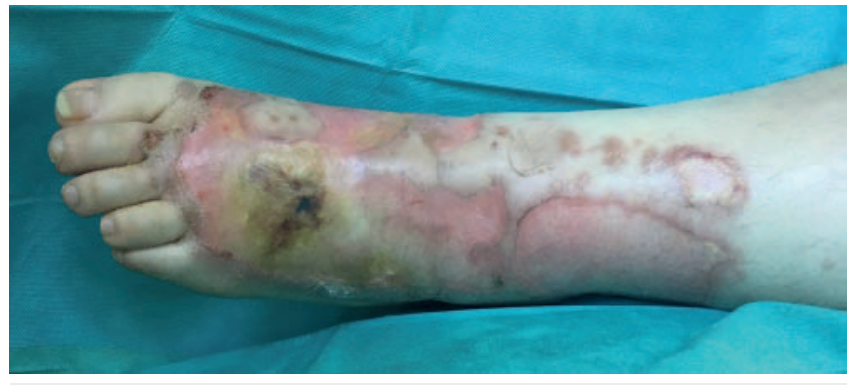

- Fig. 1 Necrosis on the dorsum of the foot, 16 days after $100 \mathrm{cc}$ extravasation of iopromid $300 \mathrm{mg} \mathrm{J} / \mathrm{ml}$ via an intravenous access at the dorsum of the foot with a power injector during a trauma CT scan without any special conservative treatment afterwards (48year-old female obese ventilated patient).

ciated edema, active cooling provides an anti-inflammatory effect via subsequent vasoconstriction [24]. At our clinic, the application of a heparin ointment dressing with cooling and thus consecutive analgesic effect has established itself as a method that is well accepted by patients. The ointment dressings are applied only to areas where the dermis is intact. Topical application is contraindicated in cases of fragile skin conditions and potential ulceration. We should note that in the course of preparing this paper, we also could not find any evidence for the traditional application of heparin or other topical methods [25]; nonetheless, the topical use of non-steroidal anti-inflammatory drugs with regard to analgesic and anti-inflammatory action with significant risk reduction of systemic side effects has been well researched [26, 27]. In their guidelines, Bellin et al. recommend the application of cold compresses in the area of the injection site for 15 to 60 minutes three times a day for up to three days or until symptoms are no longer evident [4].

There should be an immediate initial assessment with a clinical examination and monitoring of sensitivity, blood flow and any blistering or ulcerations as well as increased swelling. We recommend consultation with a (plastic) surgeon as needed in the event of circulatory or sensory disturbances or skin necrosis, blisters or ulcerations. In cases of unremarkable blood flow and sensitivity, clinical monitoring should be performed after one and four hours if necessary.

Splinting and immobilization are especially recommended at constricted areas such as wrists and ankles. In this case, the splints should be applied to include the adjoining joint (e. g. in the event of critical extravasation on the back of the hand, a palmar splint including the wrist and fingers). There are no meaningful scientific publications regarding the use of splints for contrast medium extravasation. This approach is recommended despite the absence of supporting medical literature, since the use of splints in surgery of the extremities corresponds to the clinically accepted standard of basic care for unstable wounds and infections, regardless of their formation (infected wounds, wound healing disorder, phlebitis, etc.); furthermore, use of splints also achieves some pain relief.

Finally, it should be mentioned - as in any medical complication - patients should be adequately informed regarding further procedure and potential risks in the case of contrast medium 
extravasation. In particular, patients should be made aware that if the symptoms worsen, they should go directly in the radiology department or the emergency department of the hospital.

\section{Invasive therapy for contrast medium extravasation}

\section{Hyaluronic acid injection}

The literature describes administration of hyaluronidase via the point at which the contrast medium has exuded into the surrounding tissue. There is no consensus regarding dosage, the data range from five to 250 units [11]. Injection of hyaluronic acid into the extravasated area is based on the following pathomechanism: As a mucopolysaccharide, hyaluronic acid essentially determines the structure of interstitial connective tissue. Hyaluronidase enzymatically cleaves this structure and contributes to the distribution of the extravasate, thus promoting its absorption into the vascular and lymphatic system [28]. The enzymatic effect takes place within minutes and is time-limited.

In this context, the following articles have been primarily cited: In 1998, Federle et al. [12] retrospectively studied the frequency and effect of ionic, high-osmolar, and low-ionic, non-osmolar contrast agent extravasation, demonstrating that there is no relationship between injection rate and frequency or quantity of the leaked contrast agent, and that the extravasation rate using power injectors increases when compared to manual injection. The study expressed doubts about the effectiveness of hyaluronidase therapy, since even high-volume patients without this treatment did not require surgical intervention. The 1996 article by Cohan et al., [11] also frequently cited in connection with contrast agent extravasates and hyaluronidase, provides a review of the detection, prevention and status of treatment options for contrast medium extravasation. However, this work cites many references which include the extravasation treatment of other agents. The authors conclude that the situations cited are anecdotal case studies without case control and that hyaluronidase therapy is not a routine intervention.

In a 1984 animal study of extravasation in which no contrast medium extravasation was examined, the authors only express the hypothetical conclusion that the positive effect of hyaluronidase according to the mechanism of action is to be expected for other agents [28]. In contrast, animal studies by McAlister et al. [29] in 1971 evaluated the immediate and subsequent histological effects of various ionic high osmolar contrast agents on the subcutaneous and intramuscular tissues which always show an acute inflammatory response with secondary muscle atrophy and scar formation after eight weeks. It was demonstrated that application of 25 units of hyaluronidase into the extravasate actually increased the inflammatory response with consequent coagulation and scarring. In their study, Vandeweyer at al. describe eleven cases of extravasation treated with irrigation and aspiration without the use of hyaluronidase, and mention hyaluronidase only as a conservative treatment option [30].

In summary, the data do not provide any evidence for the use of hyaluronidase as a therapy for contrast medium extravasation.
The literature contains anecdotal case studies involving contrast agents no longer in use. In our view, this therapeutic approach should be used as an emergency concept in the sense of off-label use such as in the case of inoperable patients and contrast medium-associated compartment syndrome.

\section{Aspiration and irrigation}

A further therapeutic approach is local dilution followed by aspiration, called wash-out, aspiration and suction in the literature [30]. Stab incisions are made around the affected area under local or general anesthesia, and the extravasate is aspirated with blunt suction cannulas. Subsequently the undermined tissue region is irrigated. Information about the required number of stab incisions or the volume and type of irrigation solution varies. This procedure should be performed within a time window of six hours after the extravasation event.

A 1993 article by Gault et al. [19] is frequently cited regarding this procedure in relation to contrast media. This retrospective study describes 96 extravasation patients, 44 of whom were successfully treated with irrigation and suction. However, since only one patient with contrast agent-associated extravasation was included in this population, the effectiveness of this treatment remains open with respect to radiological practice.

Loth et al. [31] retrospectively describe five cases of extravasation of ionic high-osmolar contrast media without providing exact data regarding the volume. Surgical drainage and irrigation was described as successful using several liters of Ringer's lactate in four of the five cases, which is explained by the observation of a therapeutic time window of six hours after the extravasation occurrence.

Vandeweyer at al. [30] describe eleven cases of extravasation between 20 and $90 \mathrm{ml}$ of an ionic, high-osmolar contrast medium solution and which could be successfully treated within the first two hours after the event by suction and irrigation. The clinical presentation is described by the authors with local pain without circulatory or sensory disturbances, and in two of the eleven cases with blistering.

In summary, the few anecdotal publications regarding this approach only present extravasation therapies for no longer used highly osmolar contrast media with volumes greater than $20 \mathrm{ml}$. We currently see an indication for this apparently mechanistically plausible, but not evidence-based and relatively invasive surgical procedure in the treatment of drug-based, cytotoxic extravasation, but less so in the treatment of non-ionic low-molecular contrast agent extravasation.

\section{Manual squeezing technique}

Less widespread, but described as effective and easy to perform, is the so-called manual squeezing technique in which the extravasate is manually expressed after various punctures or stab incisions.

In 2007 Tsai et al. [32] described their positive experiences with this technique in a retrospective study over the course of three months in which there were 8 extravasations between 50 $80 \mathrm{ml}$ leading to noticeable vascular impairment in the form of cold and numbness. In seven cases nonionic, low osmolar contrast 

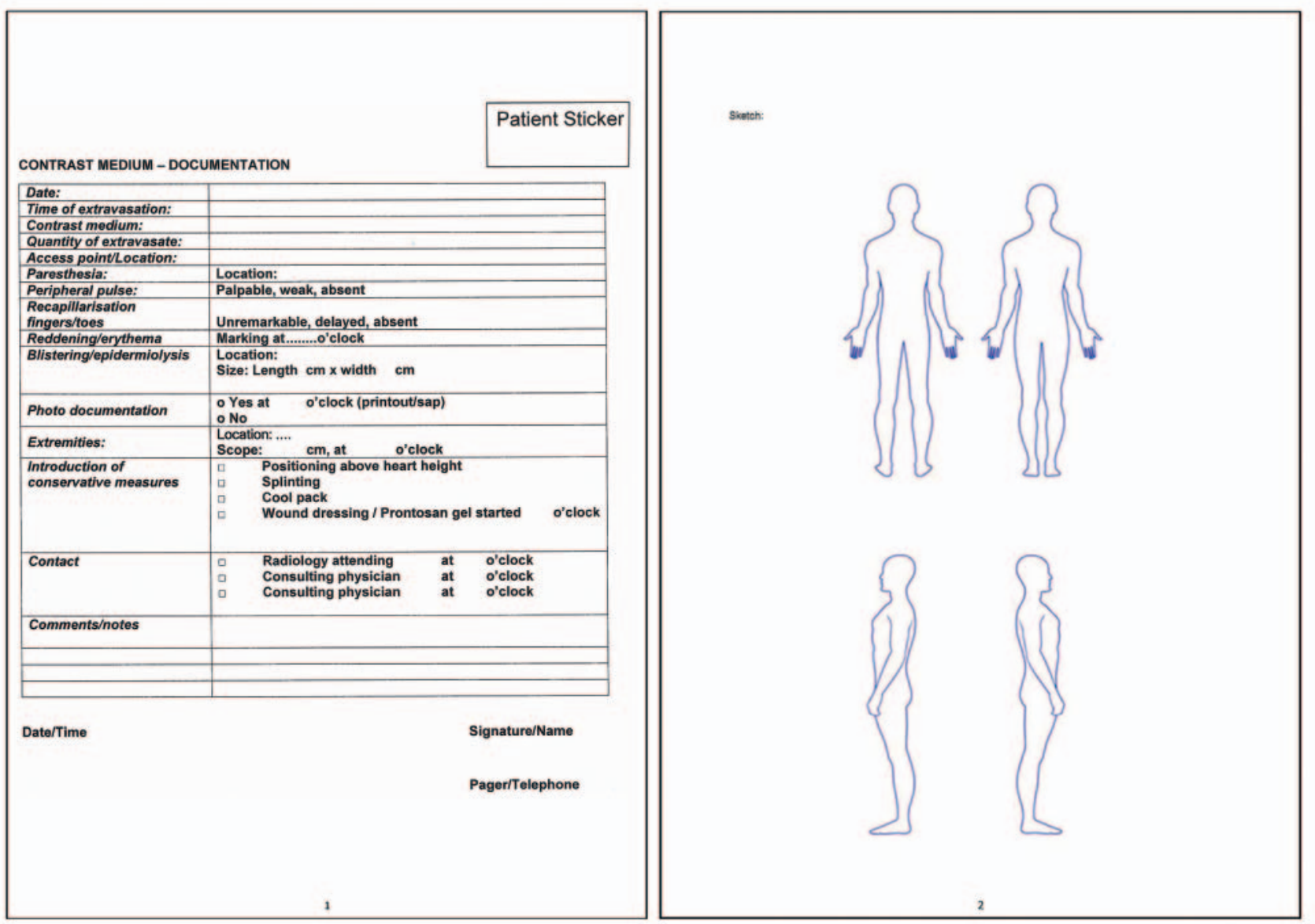

- Fig. 2 Suggestion for documentation of extravasation for contrast media. The document can be downloaded at https://www.drg.de/de-DE/ 4338/kontrastmittel-paravasate/.

medium was employed, in one case ionic, high-osmolar contrast had been used. The catheter was immediately removed, the affected area disinfected, five to eight punctures generated with an 18 gauge needle, and the fluid manually expressed. All eight cases healed satisfactorily.

In $2016 \mathrm{Kim}$ et al. [5] published an account of 23 patients with contrast medium extravasation who reported severe pressure on the limb or cases in which the extravasation volume was greater than $50 \mathrm{ml}$. The squeezing technique was applied to all 23 patients, with extravasation volumes ranging from 5 to $140 \mathrm{ml}$. After catheter removal, five to ten stab incisions of three millimeters in length were placed around the access point after disinfection. This squeezing maneuver was carried out until the extravasate leak dried up. Apart from temporary, mild epidermolysis and blistering, all cases healed without consequences within a week. A control group was not described in this study.

In summary, no adequate evaluation of the squeezing technique is possible due to the very limited available data. From our point of view, the decisive advantage appears to be the possibility to perform this procedure immediately after occurrence of extravasation before diffuse contrast medium imbibition of the tissue takes place.

\section{Fasciotomy and compartment release}

Fasciotomy is part of the standard repertoire of surgical emergency interventions, therefore this technique need not be explained here. Pathophysiologically, it is known that subcutaneous edema can cause skin necrosis, but can also lead to compartment syndrome due to the increase in intracompartmental pressure [33]. Likewise, the vicious circle underlying edema and ischemia has been described in the literature [34]. Highly osmolar or toxic agents cause edema which puts pressure on compartments thus triggering tissue ischemia. The latter, in combination with venous congestion and low arterial gradients, increases the formation of edema by capillary leakage and finally leads to necrosis, whereby the risk of necrosis is disproportionately high in relation to the time sequence.

The literature contains various case reports on the development of compartment syndrome after contrast agent extravasation [35, 36]. Fallscheer et al. [37] described the largest series in 2007 in which a group of seven patients were studied retrospectively. After the application of hyperosmolar, non-ionic contrast medium extravasation had occurred and which, according to practice of that hospital, was treated by means of fasciotomy and compartment release. The quantity of extravasate in the 


\section{Contrast Medium Extravasation}

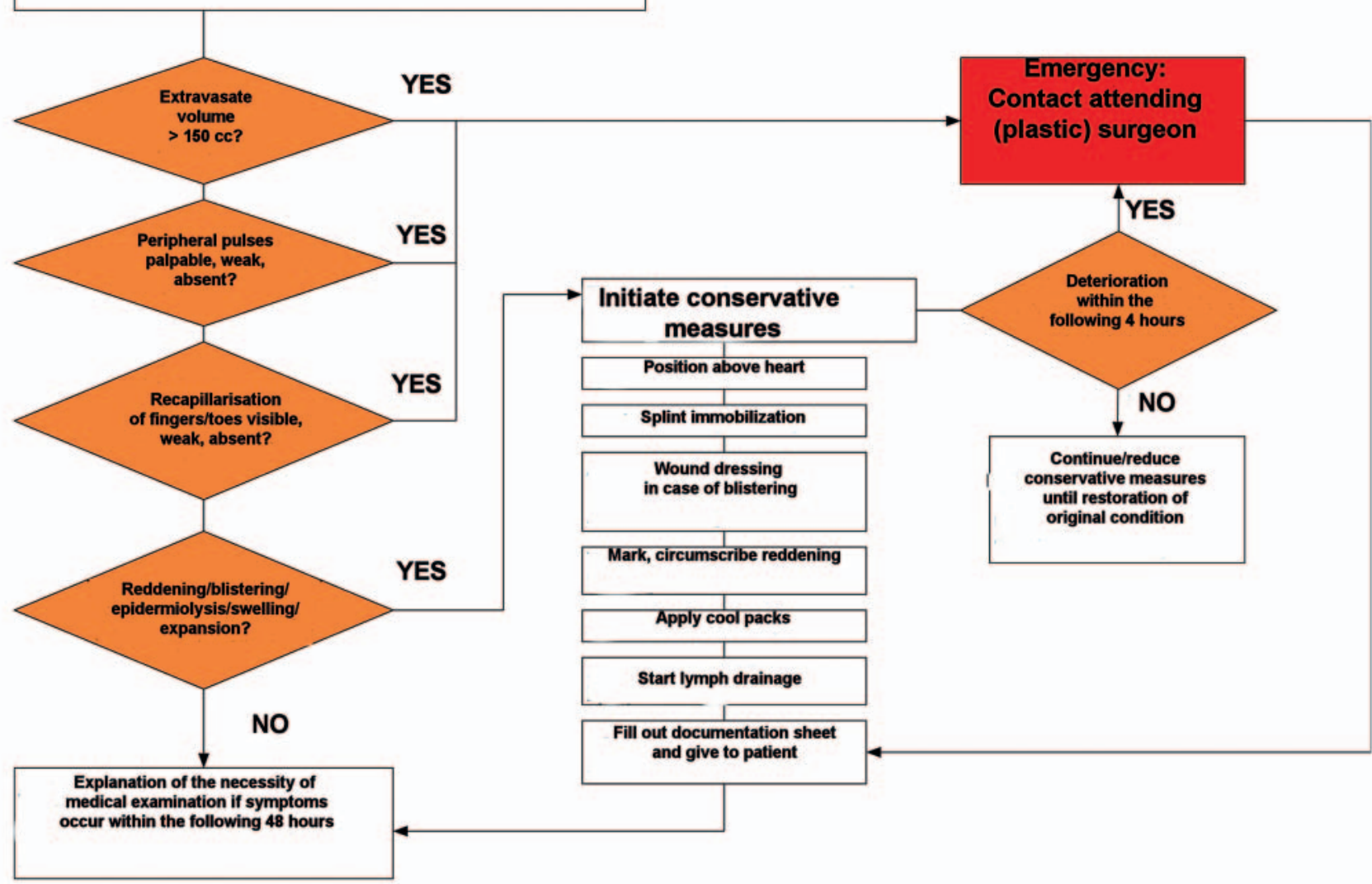

- Fig. 3 Flow-Chart for radiological contrast media extravasation. The flow-chart was prepared in collaboration with the DGPRÄC (German Society for Plastic, Reconstructive and Aesthetic Surgery) and can be downloaded at https://www.drg.de/de-DE/4338/kontrastmittel-paravasate/.

patient cohort who did not receive surgery is not described in the study. Significant swelling associated with paresthesia or circulatory disturbance or swelling combined with painful active flexion and passive extension of the affected muscle groups is considered an indication for surgical intervention. Intraoperatively, subcutaneous edema was the primary concern, with the time between detection and surgery ranging from 90 to 300 minutes. All extremities could be preserved. Postoperative complications described by the authors were temporary movement restrictions, residual lymphoedema and chronic regional pain syndrome (CRPS type 1). The authors report that after switching to new, safer power injectors in conjunction with a standardized test injection of $20 \mathrm{ml}$ saline, there was no reduction in the number of extravasations, but events were recorded faster, and conservative therapy procedures could be initiated, making surgical treatment unnecessary.

\section{Summary}

Considering the aforementioned invasive therapy procedures for contrast medium extravasation, it is striking that in general these case studies are largely retrospective, entail a series of small num- bers of cases without conservative control groups, some of which originate far in the past which are no longer comparable with contrast agents currently in use. On the other hand, there are current reports on the successful management of extravasation.

In their 2010 retrospective study, Sbitany et al. [38] questioned the need for involvement of a plastic surgeon for contrast medium extravasation greater than $30 \mathrm{ml}$. According to their series of 102 patients, each of whom healed free of complications without surgery, the authors conclude that due to generalized changeover to non-ionic agents, severe complications no longer arise [21, 39, 40]. Likewise, greater extravasation volumes of up to $150 \mathrm{ml}$ can be conservatively treated without consequence [41]. However, it would be incorrect to conclude that restoration to the patient's original condition can be presumed. Contrast medium extravasation continues to be a serious complication which should be treated according to definite recommendations.

The personnel involved should be aware of the related risk factors. In individual cases, depending on the radiological problem, for at-risk patients it should be considered whether the planned examination would allow a lower contrast flow rate. In addition, catheters that fail to inject a test bolus or permit aspiration, or 
where the surrounding tissue is indurated and/or reddened, as well as assesses to small or peripheral vessels of the lower extremities should not be used.

In the case of extravasation, careful documentation of the following parameters is obligatory in order to be able to recognize deteriorations in findings at an early stage and respond adequately: type of contrast agent, amount of extravasation, time of examination, location of access, and, if possible, sensitivity of affected extremity, blood flow and status of peripheral pulses ( $>$ Fig. 2). Furthermore, information about skin status, possible epidermiolysis and blistering or erythema should be provided. If skin changes are present, we recommend marking the extent and, if possible, photographic documentation and size determination at a clearly defined location (anatomical fixed points). Documentation should be stored in the HIS (Hospital Information System) or in the patient file, if possible, in order to be accessible to all practitioners.

In summary, we agree with Sbitany et al. [38] in recommending consultation with a plastic surgeon in the event of extravasation volumes greater than approx. $150 \mathrm{ml}$. Exceptions are cases in which there is a visible impairment of the soft tissues, sensory or circulatory disorders independent of the amount of extravasate; in such cases inclusion of a plastic surgeon should take place as an emergency measure. An algorithm of our recommendations for extravasation, which was developed under the patronage of the German Society of Plastic, Reconstructive and Aesthetic Surgeons (DGPRÄC) ( $>$ Fig. 3), can be downloaded from the Internet as a DIN A4 printout at https://www.drg.de/de-DE/4338/kontrastmittel-paravasate/.

Thanks to modern technology and innovations in pharmacology, the risk of serious consequences after contrast media extravasation has fortunately been significantly reduced [37, 38]. However, the occurrence of extravasation is not declining, only the incidence of consequential damage, meaning that severe complications in the form of tissue necrosis and compartment syndrome can still occur even after extravasation in small volumes [41, 42]. Since there are no clear risk criteria for the development of complications with serious consequences, and since these cases are rarities, it is important to remain vigilant with all contrast medium extravasations and to regularly check the incidence in your own department in order to eliminate possible sources of risk.

\section{Conflict of Interest}

The authors declare that they have no conflict of interest.

\section{References}

[1] Bae KT. Intravenous contrast medium administration and scan timing at CT: considerations and approaches. Radiology 2010; 256: 32-61

[2] Sum W, Ridley LJ. Recognition and management of contrast media extravasation. Australas Radiol 2006; 50: 549-552

[3] Lewis GB, Hecker JF. Radiological examination of failure of intravenous infusions. Br J Surg 1991; 78: 500 - 501

[4] Bellin MF, Jakobsen JA, Tomassin I et al. Contrast medium extravasation injury: guidelines for prevention and management. Eur Radiol 2002; 12: $2807-2812$
[5] Kim SM, Cook KH, Lee I] et al. Computed tomography contrast media extravasation: treatment algorithm and immediate treatment by squeezing with multiple slit incisions. Int Wound J 2017; 14: 430-434

[6] Pacheco Compana F], Gago Vidal B, Mendez Diaz C. Extravasation of contrast media at the puncture site: Strategies for managment. Radiologia 2014; 56: 295-302

[7] Nicola R, Shaqdan KW, Aran S et al. Contrast Media Extravasation of Computed Tomography and Magnetic Resonance Imaging: Management Guidelines for the Radiologist. Curr Probl Diagn Radiol 2016; 45: $161-164$

[8] Chew FS. Extravasation of iodinated contrast medium during CT: self-assessment module. Am J Roentgenol 2010; 195: S80-S85

[9] Radiology ESoG. ESUR contrast media guidelines.

[10] radiology Aco. ACR manual on contrast media. 2013

[11] Cohan RH, Ellis JH, Garner WL. Extravasation of radiographic contrast material: recognition, prevention, and treatment. Radiology 1996; 200: $593-604$

[12] Federle MP, Chang PJ, Confer S et al. Frequency and effects of extravasation of ionic and nonionic CT contrast media during rapid bolus injection. Radiology 1998; 206: 637-640

[13] Cohan RH, Bullard MA, Ellis JH et al. Local reactions after injection of iodinated contrast material: detection, management, and outcome. Acad Radiol 1997; 4: 711-718

[14] Niv G, Costa M, Kicak P et al. Vascular extravasation of contrast medium in radiological examinations: University of California San Diego Health System Experience. J Patient Saf 2014; 10: 105-110

[15] Jacobs JE, Birnbaum BA, Langlotz CP. Contrast media reactions and extravasation: relationship to intravenous injection rates. Radiology 1998; 209: $411-416$

[16] Shaqdan K, Aran S, Thrall J et al. Incidence of contrast medium extravasation for $\mathrm{CT}$ and MRI in a large academic medical centre: a report on 502391 injections. Clin Radiol 2014; 69: 1264-1272

[17] Langstein HN, Duman H, Seelig D et al. Retrospective study of the management of chemotherapeutic extravasation injury. Ann Plast Surg 2002; 49: 369-374

[18] Hawi N, Citak M, Liodakis E et al. Development of compartment syndrome after intravenous administration of an X-ray contrast medium. Recommendations on acute therapy regimens. Unfallchirurg 2014; 117 : $374-379$

[19] Gault DT. Extravasation injuries. Br J Plast Surg 1993; 46: 91 - 96

[20] Hao D, Ai T, Goerner F et al. MRI contrast agents: basic chemistry and safety. J Magn Reson Imaging 2012; 36: 1060 - 1071

[21] Cohan RH, Leder RA, Bolick D et al. Extravascular extravasation of radiographic contrast media. Effects of conventional and low-osmolar agents in the rat thigh. Invest Radiol 1990; 25: 504-510

[22] Cochran ST, Bomyea K, Sayre JW. Trends in adverse events after IV administration of contrast media. Am J Roentgenol 2001; 176: 1385-1388

[23] Khan MS, Holmes JD. Reducing the morbidity from extravasation injuries. Ann Plast Surg 2002; 48: 628-632; discussion 32

[24] Hastings-Tolsma MT, Yucha CB, Tompkins J et al. Effect of warm and cold applications on the resolution of i.v. infiltrations. Res Nurs Health 1993; 16: $171-178$

[25] Sznitowska M, Janicki S. Percutaneous absorption of heparin: a critical review of experimental results. Pol Merkur Lekarski 2000; 7: 58-63

[26] Massey T, Derry S, Moore RA et al. Topical NSAIDs for acute pain in adults. Cochrane Database Syst Rev 2010: CD007402

[27] Ng L, Monagle K, Monagle P et al. Topical use of antithrombotics: review of literature. Thromb Res 2015; 135: 575-581

[28] Laurie SW, Wilson KL, Kernahan DA et al. Intravenous extravasation injuries: the effectiveness of hyaluronidase in their treatment. Ann Plast Surg 1984; 13: $191-194$ 
[29] McAlister WH, Kissane JM. Comparison of soft tissue effects of conventional ionic, low osmolar ionic and nonionic iodine containing contrast material in experimental animals. Pediatr Radiol 1990; 20: 170-174

[30] Vandeweyer E, Heymans O, Deraemaecker R. Extravasation injuries and emergency suction as treatment. Plast Reconstr Surg 2000; 105: 109110

[31] Loth TS, Jones DE. Extravasations of radiographic contrast material in the upper extremity. J Hand Surg Am 1988; 13: 395-398

[32] Tsai YS, Cheng SM, Ng SP et al. Squeeze maneuver: an easy way to manage radiological contrast-medium extravasation. Acta Radiol 2007; 48: $605-607$

[33] Chan PS, Steinberg DR, Pepe MD et al. The significance of the three volar spaces in forearm compartment syndrome: a clinical and cadaveric correlation. J Hand Surg Am 1998; 23: 1077 - 1081

[34] Lanz U, Felderhoff ]. Ischemic contractures of the forearm and hand. Handchir Mikrochir Plast Chir 2000; 32: 6-25

[35] Benson LS, Sathy M], Port RB. Forearm compartment syndrome due to automated injection of computed tomography contrast material. J Orthop Trauma 1996; 10: 433-436
[36] Memolo M, Dyer R, Zagoria RJ. Extravasation injury with nonionic contrast material. Am J Roentgenol 1993; 160: 203-204

[37] Fallscheer P, Kammer E, Roeren T et al. Injury to the upper extremity caused by extravasation of contrast medium: a true emergency. Scand J Plast Reconstr Surg Hand Surg 2007; 41: 26-32

[38] Sbitany H, Koltz PF, Mays C et al. CT contrast extravasation in the upper extremity: strategies for management. Int J Surg 2010; 8: 384-386

[39] Kim SH, Park JH, Kim Yl et al. Experimental tissue damage after subcutaneous injection of water soluble contrast media. Invest Radiol 1990; 25: $678-685$

[40] Cohan RH, Dunnick NR, Leder RA et al. Extravasation of nonionic radiologic contrast media: efficacy of conservative treatment. Radiology 1990; 176: $65-67$

[41] Wang CL, Cohan RH, Ellis JH et al. Frequency, management, and outcome of extravasation of nonionic iodinated contrast medium in 69657 intravenous injections. Radiology 2007; 243: 80-87

[42] Wienbeck S, Fischbach R, Kloska SP et al. Prospective study of access site complications of automated contrast injection with peripheral venous access in MDCT. Am J Roentgenol 2010; 195: 825-829 